\title{
SOIL STABILIZATION OF THE SOIL BY USING DIFFERENT WASTE MATERIALS - A REVIEW
}

\author{
Tanna Manohar ${ }^{1}$, Jyoti Prakash Giri ${ }^{2}$ \\ ${ }^{I} P G$ Student, Department of Civil Engineering, GMR Institute of Technology, Rajam, AP, 532127. \\ ${ }^{2}$ Assistant Professor, Department of Civil Engineering, GMR Institute of Technology, Rajam, AP, 532127.
}

Article DOI: https://doi.org/10.36713/epra8334

DOI No: 10.36713/epra8334

\begin{abstract}
Soils that expand and contract unexpectedly are often described in terms of their permeability and poor load transfer mechanism. As a result of these qualities, the rate of failure mechanisms such as excessive settlement and subgrade failures attains at a very rapid pace, and the expansive soils are defined as more sensitive than other types of soil. Constructions based on this sort of soil are therefore challenging for an Engineer to complete. Growing population has led to an uncontrolled increase in plastic waste creation, and the disposal of the plastic waste has become a significant issue for all countries. As a result, road construction industry has shown a great deal of interest in utilising this waste and researchers have attempted to produce plastic wastes in soil stabilization as a strengthening agent. The focus of this study is to identify ways to make use of plastic wastes in geotechnical applications on a large scale.
\end{abstract}

KEYWORDS: Soil stabilization, Plastic waste, Unconfined compressive strength, Static tensile strength

\section{INTRODUCTION}

The world has seen a huge growth in the population in the last few decades due to the population rising the needs of the people are increasing. These are the days where plastics have been became part in our day to day activities.to meet the demands of the people the plastic generation should be high.as the plastic is the nonbiodegradable material the disposal of waste plastic is problem. According to central pollution control board around 3.3 million metric tons of waste plastic produced in India in the year of 2018-2019.The disposal of enormous amount of plastic is difficult. So researches had been done to use the waste plastic in the fields of civil engineering. One of the civil engineering field that the plastic is used in is stabilization of soil. In India majority of the soil is not suitable for the construction. The majority of soil is expansive and cohesion less soil. These two types of soil exhibits low engineering properties. For construction of any building or the roads on these soils all the times it is not possible. So stabilization need to be done to improve the properties of these soils and make it utilize . Utilization of the waste plastic in the soil stabilization can be helpful in increasing the engineering properties of soil. Various plastic materials that are used for the stabilizing the soil is

- Polyethylene Terephthalate (PETE)

- High-Density Polyethylene (HDPE)

- Low density polyethylene (LDPE)

- Polyvinyl Chloride (PVC - U)

- Polypropylene (PP)

- Polystyrene or Styrofoam (PS)

- Poly acrylic.

The above materials are made into fibres with maintaining aspect ratio and they are added into the soil by maintaining an proportion. With the addition of the waste plastic to the soil the disposal problems can be reduced up to certain extent. In this study the utilization of various types of plastic materials in different types of soils had been studied.

\section{LITERATURE REVIEW}

(Choudhary, 2018, November.) stated that the addition of the LDPE increases the CBR value.CBR values for the unsoaked increases by increasing the strip content and reaches highest at a strip content of $1 \%$ and aspect ratio of 1 and after that it decreases by increasing strip content. Similar case is observed in the soaked CBR. In this the plastic is taken in three aspect ratios 
maintaining width $10 \mathrm{~mm}$ and varying the lengths $10 \mathrm{~mm}, 20 \mathrm{~mm}, 30 \mathrm{~mm}$ and they were added in the percentages of $0.5,1,2 \%$. It is observed that with the addition of waste LDPE of $1 \%$ with aspect ratio 1 the thickness of the layer decreases by $20.91 \%$.

(Panda, 2020) in this they examined the effect of using waste polyethylene terephthalate (PETE) strips in the expansive soil. In this the soil is collected from the Attabira, Bargarh District of Odisha. The soil was classified as $\mathrm{CH}$ (high plastic clay) as per Classification (IS:1498-1970) In this they performed tests of CBR for obtaining the efficient percentages of PETE strips at which maximum strength is obtained. In this investigation, the ideal estimations of CBR tests were gotten at the adding of $4 \%$ of PETE strips. By this study it was concluded that the soil stabilized with PETE strips has good CBR value.

(Abukhettala, 2021) in this they examined the effect of using the LDPE, HDPE, PET and PP in the soil. The HDPE pellets and PET plastic used in this research are cylindrical in shape, with diameters across $3.65 \mathrm{~mm}$ and $4.45 \mathrm{~mm}$ and thicknesses across $2.70 \mathrm{~mm}$ and $1.65 \mathrm{~mm}$ respectively. The pellets had a round shape and are 3.3 $\mathrm{mm}$ in dia, while the flakes were triangular, between 7 $\mathrm{mm} \times 8.8 \mathrm{~mm}$ in diameter and $0.7 \mathrm{~mm}$ in thickness. In this they conducted the tests of UCS, CBR, permeability and resilient modulus. The percentage of plastic added to the soil is $1 \%, 2 \%, 3 \%, 4 \%, 5 \%$ and $10 \%$. They found that due to the addition of $2 \%, 4 \%$ and $10 \%$ PP and HDPE pellets permeability of the soil increases. But due to the addition of the plastic the there is no significant change in the resilient modulus when mixed with plastic and the friction of the reinforced soil decreases when mixed plastic. (Shah, 2020) in this he investigated the use of waste plastic in the form of geocell and geo grid. The soil is classified as SM silty sand. By cutting the plastic containers of width $1.5 \mathrm{~cm}$ the geo grids are made in the size of $1.5 \mathrm{~cm} \times 3 \mathrm{~cm}$. The round neck of the plastic bottle is used for making geocell. These geogrids and geo cells are placed individually at a depth of $2.5 \mathrm{~cm}, 5 \mathrm{~cm}, 7.5 \mathrm{~cm}$ in the CBR mould and the CBR tests are done. It is observed that the CBR results for the virgin soil is $4 \%$ and for the soil reinforced with the geo rids at depth of $2.5 \mathrm{~cm} 5 \mathrm{~cm}$ $7.5 \mathrm{~cm}$ are $4.5,10.5,4.5 \%$ and for the geo cell are $6.5,11,14 \%$ respectively. By the investigation it is observed that the waste geocell grid placed at a depth of $5 \mathrm{~cm}$ from the top of the CBR is effective. When the waste plastic geo cell is placed at a depth of $7.5 \mathrm{~cm}$ the load carrying capacity of the soil is more when compared with the geo grid. By the study it was concluded that the plastic made in the form of geo cell and geo grid can be used as the reinforcing material.
(Mishra, 2018) investigated the use of PET fibres in combination of fly ash. The soil is classified as CL according to the USCS classification. The PET added in the percentage of $0.4 \%, 0.8 \%, 1.2 \%, 1.6 \%$ and fly ash added in combination percentage of $5 \%, 10 \%, 15 \%, 20 \%$ .CBR, ITS and the shear tests are done to determine the strength parameters. The value of $\mathrm{CBR}$ at $1.2 \% \mathrm{PET}$ fiber $+15 \%$ fly ash is found effective. Here by increasing the PET fibre percent mixed with fly ash the shear strength of reinforced soil increases with the adding of $1.2 \%$ PET fibres and fly ash $15 \%$. The shear strength of reinforced soil develop 1.45 times of shear strength of the un-reinforced soil. The cohesion and the angle of internal friction increases with an increment in PET fibre content in blend with fly ash. By the study it is found that PET along with the combination of fly ash can be used in the stabilization of the weak soils as well as in the development of the sub grade.

(Yadav, 2019) had examined the use of polypropylene and polyethylene in the clayey soil. The soil is observed as CL according to USCS classification. The PP and PET fibres were added in the percentages of 1,2,3,4 individually to the soil with length $1 \mathrm{~cm}, 2 \mathrm{~cm}$. Various test are done to determine soil properties. The tests that performed are the standard compaction test, unconfined compressive strength test, California Bearing Ratio test, and resilient modulus increase. For the UCS soil mixed with PP and PE fibre of length $2 \mathrm{~cm}$ and proportion $1 \%$ is effective. With the increase in the fibre content the resilient modulus increases. The CBR value increases gradually with the addition of the fibre content but it is optimum at $4 \%$ of fibre content and of length $2 \mathrm{~cm}$. Hence by the study it is observed that the PP and PE fibres can be utilise in the development of the weak sub grades.

(Bekhiti, 2019) examined the effect of using the scrap tire with the cement in the expansive soil. The soil is classified as $\mathrm{CH}$ according to USCS. In this research, three different rubber fibre ratios $0,0.5,1,2 \%$ and four different cement ratios $0,5,7.5,10 \%$ by weight of soil, are used. The tests were conducted to know the shear strength. In this by the addition of the rubber content the shear strength of the soil increases and the ductility index of the soil increases and it is observed that $2 \%$ of the fibre content is effective.by the research it is found that the scrap tires can be effectively used in the soil stabilization.

(Kumar, 2020) had investigated the usage of e-waste in the cohesion less soil. Here the plastic of e-waste is added in the percentage of $3 \%, 6 \%, 9 \%$. The shear strength characteristics are determined by conducting direct shear test, UCS. By the addition of e-waste the unconfined compressive strength increases by $56 \%$ when compared with the soil mix without the e-waste. 


\section{EPRA International Journal of Research and Development (IJRD)

In the direct shear test the value increase by $60 \%$ with the addition of the e-waste.

(Fauzi, 2013) had examined the effect of using HDPE and glass content in the clayey soil. The HDPE added in the percentage of $4 \%, 8 \%, 12 \%$ to the weight of the soil. Atterberg limit tests were carried out to determine the properties of soil. With addition of HDPE and glass content the properties like plastic limit liquid limit and plastic limit increases. The CBR value rises with the increase in the content of HDPE and glass content.

(Yadav, 2019) investigated the use of the rubber fibres and cement in the clayey soil. The rubber fibres and rubber granules are added in the percentages of $2.5 \%, 5 \%, 7.5 \%, 10 \%$ and cement added in the percentage of $3 \%, 6 \%$ and then the rubber $(2.5,5,7.5,10)$ and cement $(3,6)$ are combined and added to soil. The modified compaction, consolidation, UCS, STS tests are conducted to evaluate the various parameters of soil. wetting and drying tests are conducted to determine the durability of the soil mixed with the cement and the rubber fibre. It is observed that addition of the rubber fibre increases the compression index. The clay soil mixed with $6 \%$ of cement and carrying $0 \%$ and $2.5 \%$ rubber fibre full fills the rule of $20 \%$ weight loss in the durability tests.

(Tiwari, 2020) studied the effect of using the polypropylene with the silica fume. The polypropylene fibre added in the proportion of $0 \%, 0.25 \%, 0.50 \%, 1 \%$ and silica fume added in the proportion of $2 \%, 4 \%$, and $8 \%$ have been added to the dry weight of the soil. the SF and PP are added individually with the percentages mentioned above and after SF and PP are combinedly added to the soil. The soil is classified as high plastic clay (CH). (Kumar, 2020)The CBR value of the soil increases with addition of SF and PP but the maximum increase is observed at addition $8 \% \mathrm{SF}+0.25 \% \mathrm{PP}$ at this proportion the CBR values increase by $107.89 \%$.the free swell index and liquid limit value decrease by adding of SF and PP.

(Abdelsalam, 2019)investigated the usage of HDPE bits in the cohesion less soil. Direct shear test, onedimensional consolidation test were conducted to determine the shear strength and consolidation characteristics of the soil. The HDPE bits are added in the percentage of $0 \%, 5 \%, 10 \%$ and $15 \%$. The $\mathrm{c}$ and $\varnothing$ values of the soil mixed with the HDPE bits increases from $26 \mathrm{kPa}$ and $37^{\circ}$ to $45 \mathrm{kPa}$ and $46^{\circ}$, respectively as the HDPE content increased from 0 to 15 percent. The compressibility and coefficient of permeability of soil increases by adding $5 \%$ of HDPE bits.

(Peddaiah, 2018)This research covers the study of the influence of plastic bottle strips on silty sand, for which a number of compaction, direct shear, and California bearing ratio tests have been performed on it.Experiments have been carried out with adding plastic in the percentages of 0.2,0.4,0.6 and 0.8 and plastic strips maintained length of $(15 \mathrm{~mm} \times 15 \mathrm{~mm})$ $(15 \mathrm{~mm} \times 25 \mathrm{~mm}) \quad(15 \mathrm{~mm} \times 35 \mathrm{~mm})$. With plastic reinforcement in soil, there is a substantial increase in maximum dry unit weight, Shear Strength Parameters, and CBR value, among other things. The CBR values for the soil increases from 3.3 to 7.1 for $0.2 \%$ plastic and 3.3 to 16.5 for $0.4 \%$ plastic The amount of improvement in soil characteristics that occurs is dependent on the kind of soil, the amount of plastic in the soil, and the size of the strip. Improvements in engineering characteristics of silty sand are found in the research when plastic content is 0.4 percent and strip size $15 \mathrm{~mm} \times 15 \mathrm{~mm}$. Hence by the study it is found that the waste plastic can be used in the pavement sub grades and the geo technical applications.

\section{CONCLUSIONS}

By the literature study it is found that, due to inertness to chemical and physical reactions waste plastic such as LDPE, HDPE, PE, PP may be utilised in varied weather situations. They are readily available and inexpensive; therefore, they are an excellent choice for soil stabilisation. By the researches it is observed that, the addition of the plastic helps in improving the properties of the soil make the soil suitable for road construction. Addition to this maintaining the strip length and the proportions it is found the shear strength values and the California bearing ratio values increases in the performance point of view in long term implementation.

\section{REFERENCES}

1. Abdelsalam, Z. A. (2019). Reinforcing Some Kuwaiti Soils with Shredded High-density Polyethylene (HDPE) Bits. . Environmental \& Engineering Geoscience, 25(3),, pp.213-221.

2. Abukhettala, M. a. ( 2021). Geotechnical characterization of plastic waste materials in pavement subgrade applications. Transportation Geotechnics, 27, p.100472.

3. Bekhiti, M. T. (2019). 1. Influence of waste tire rubber fibers on swelling behavior, unconfined compressive strength and ductility of cement stabilized bentonite clay soil. Construction and Building Materials, 208,, pp.304-313.

4. Choudhary, A. D. (2018, November.). Improvement of Properties of Clay Subgrade Using Waste LDPE Strip Reinforcement. . In International Conference on Sustainable Waste Management through Design, (pp. pp. 103-115). Springer, Cham.

5. Fauzi, A. N. (2013). Experimental study on subgrade stabilization of kuantan clay soil using 
HDPE mixed with lime. In Proceeding of the 14th REEEA Conference, . Kuala Lumpur, Malaysia.

6. Kumar, J. a. (2020). Experimental analysis of soil stabilization using e-waste. Materials Today: Proceedings, 22,, pp.456-459.

7. Mishra, B. a. (2018). 1. Use of randomly oriented polyethylene terephthalate (PET) fiber in combination with fly ash in subgrade of flexible pavement.,. Construction and Building Materials , 190, pp.95-107.

8. Panda, R. a. (2020). Improvement in Engineering Behaviour of Expansive Soil Reinforced with Randomly Distributed Waste Plastic Strips. Springer Singapore., pp. 239-248.

9. Peddaiah, S. B. (2018). Experimental study on effect of waste plastic bottle strips in soil improvement. . Geotechnical and Geological Engineering, 36(5), pp.2907-2920.

10. Shah, A. a. (2020). Improving the Soil Subgrade with Plastic Waste Reinforcement-An Experimental Study. Springer, Singapore, pp. 153-161.

11. Tiwari, N. a. (2020). An experimental study on the behavior of lime and silica fume treated coir geotextile reinforced expansive soil subgrade. . Engineering Science and Technology, an International Journal, 23(5),, pp.1214-1222.

12. Yadav, J. H. (2019). Geotechnical properties of rubber reinforced cemented clayey soil. Transportation Infrastructure Geotechnology, 6(4), pp.337-354. 